\title{
The Growing-Block: Just one thing after another?
}

\author{
May 26, 2016
}

In this article, we consider two independently appealing theories - the GrowingBlock view and Humean Supervenience - and argue that at least one is false. The Growing-Block view is a theory about the nature of time. It says that (a) past and present things exist, while future things do not, and (b) the passage of time consists in new things coming into existence. Humean Supervenience is a theory about the nature of entities like laws, nomological possibility, counterfactuals, dispositions, causation, and chance. It says that none of these entities are fundamental, since if there were, this would entail the existence of irreducible necessary connections between matters of fact. Instead, these entities supervene on a fundamental, nonnomological "Humean mosaic" of property instances at spacetime points. We will further explain and motivate the Growing-Block view and Humean Supervenience in sections 2 and 3, but first, we turn to our master argument.

\section{Our Master Argument}

Our master argument for the incompatibility of Humean Supervenience and the Growing-Block view proceeds by reductio. We assume

1. Humean Supervenience and the Growing-Block view are both true.

We appeal to three additional premises, defended in sections 4, 5, and 6.

2. There are non-trivial truths about the future.

3. All non-trivial truths are made true by something (or things). 
4. If some propositions about the future are made true by something (or things) not in the future, then there are irreducible necessary connections between distinct existents.

Together with these three premises, our assumption 1 entails a contradiction.

5. Some propositions about the future are made true by something (or things) $(2,3$, quantifier reasoning).

6. The Growing-Block theory is true (1, conjunction elimination).

7. There are no future things (6, definition of the Growing-Block theory).

8. Humean Supervenience is true (1, conjunction elimination).

9. There are not irreducible necessary connections between distinct existents (8, definition of Humean Supervenience).

10. Some propositions about the future are made true by something(s) not in the future $(5,7$, quantifier reasoning).

11. There are irreducible necessary connections between distinct existents (4, 10 , modus ponens).

\section{Contradiction $(9,11)$.}

Thus, Humean Supervenience and the Growing-Block Theory are not both true. The argument is valid, and (we will argue) each of premises 2-4 is true. So we are forced to accept the conclusion. But we think this is unfortunate: both the Growing-Block view and Humean Supervenience are appealing theories. Before defending premises 1-2 we motivate each theory in turn: the Growing-Block Theory in section 2 and Humean Supervenience in section 3.

\section{The Growing-Block View}

The Growing-Block view has two commitments:

ASYMMETRIC ONTOLOGY Only past and present events exist, while future events do not. The present is thus the last time in existence. 
PASSAGE The passage of time consists in events coming into existence, so that the universe is a four-dimensional block that grows as new events are added to the later end. Once events become part of the block, their intrinsic properties and their relations to earlier states are fixed forever more, but their relations to later states can change, as later states are added to the end of the block.

These two commitments are based on two different but related intuitions.

ASYMMETRIC ONTOLOGY is based on the intuition that the future is 'open' while the past is 'fixed'. An asymmetry between past and future seems important in our deliberation, planning, intervention in, and memory of events. This intuition has a good pedigree, dating back to the ancient Greeks; Aristotle quotes the tragic poet Agathon as saying

For even from god this power is kept, this power alone:

To make it true that what's been done had never been.

[Aristotle, 2002, 1139b10]

ASYMMETRIC ONTOLOGY gives a simple explanation for this asymmetryit is a question of existence. The past is fixed because it exists, and the future is open because it does not exist. This ontological asymmetry is compatible with a causally determined future and/or a causally indeterminate past [see Briggs and Forbes, 2012].

The intuitions motivating PASSAGE are so widely shared that even critics of the Growing-Block view often accept that one needs reasons to deny PASSAGE, but not to accept it [Olson, 2009, Miller, 2008]. As Eric Olson [2009, 445] puts it, those who deny PASSAGE "have some explaining to do, because this is not how things appear." But again, the Growing-Block view provides an explanation of this intuition: the world includes a dynamic reality with an evanescent present. When time passes, reality has changed in some way, some things that were objectively present are present no longer, and some new things are objectively present.

Such is the attraction of the two intuitions: the asymmetry between past and future and the passage of time, that Kristie Miller, herself an opponent of the Growing-Block theory, labels them part of 'the intuitive view' [c.f. Miller, 2008, 179-191]. The Growing-Block view, then is a way of making the intuitive view metaphysically more precise: the asymmetry between past and future is an ontological one, and the passage of time is an ontological change-more events coming into existence. 


\section{Humean Supervenience}

Humean Supervenience "is named in honour of the great denier of necessary connections", David Hume [Lewis, 1986b, x]. Humean Supervenience denies the existence of fundamental necessary connections between distinct existents, since, as Hume argued, such necessary connections would be deeply mysterious. On the other hand, Humeans need to account for some apparent necessary connections between distinct existents: the world obeys laws, some events cause others, many objects have dispositions, and so on. Humean Supervenience claims that these modal facts are ultimately grounded in non-modal facts. ${ }^{1}$

More specifically, according to Humean Supervenience fundamental reality consists of a Humean "mosaic" made up of spacetime points and perfectly natural spatiotemporal relations that knit those spacetime points together. The points instantiate local perfectly natural properties, such as mass, charge and spin. (That the properties are local means that they pertain only to points; that they are perfectly natural means that they are ontologically privileged properties like having a mass of 1 AMU, and not gerrymandered properties like either having a mass of 1 AMU and being part of a camel or being positively charged and north of the Equator or ...)

Several categories of existence are conspicuously absent from the Humean mosaic: laws of nature, counterfactuals, dispositions, and chances. All of these categories invoke a kind of worldly modality that Humeans find questionable: laws explicitly posit necessary connections between distinct existences, while dispositions, counterfactuals, and chances all involve one part of the world (a cause, condition, or chance setup) constraining another (an effect, manifestation, or chancy outcome). We'll refer to the union of the categories on our list as "the nomological package", so that something is in the nomological package just in case it is a law, a counterfactual, a disposition, or a chance. According to Humean Supervenience, members of the nomological package must supervene on the Humean mosaic: no two worlds can differ with respect to the laws, counterfactuals, dispositions, or chances, unless they also differ with respect to the Humean mosaic.

If Humean Supervenience works, it will provide valuable philosophical benefits, enabling us to explain truths about the nomological package using only the lightweight ontology of the Humean mosaic. Beebee [2000] points out that

\footnotetext{
${ }^{1}$ [Lewis, 1986a] attempts to reduce all modality to nonmodal concepts. Our Humean needn't adopt Lewis's views on metaphysical modality; here, we are particularly interested in the reduction of nomological modality.
} 
Humean Supervenience has the resources to explain many of our platitudes about laws: that they differ from accidental generalizations; that they support counterfactuals; and that whatever is entailed by the laws is physically necessary. It is best if we can explain such things without appealing to mysterious, fundamental necessary connections-something Humean Supervenience can do, while rival views cannot.

Defenders of Humean Supervenience are typically eternalists-they believe there are not just local, particular matters of fact at this time, but also local particular matters of fact that have been, or will be. Eternalism is incompatible with the Growing-Block theory, which claims that no future things exist. Perhaps eternalism bears no deep connection to Humean Supervenience, and its popularity among Humeans is mere coincidence. Indeed, we admit that Humean Supervenience and the Growing-Block view are logically compatible. Nevertheless, Humean Supervenience is incompatible with the Growing-Block view given the three additional premises in our master argument.

In sections 4, 5, and 6, we defend those premises. We argue first, that there are truths about the future, second that those truths must be made true by something in the world, and third, that if any past or present things can do the job, they will have to bear some sort of irreducible necessary connections to future things. It follows that premise 1, the conjunction of Humean Supervenience and the Growing-Block view - the Humean Growing-Block view, for short—must be false.

\section{Non-Trivial Truths About the Future}

Some future contingents are true. Here are some examples:

(E) There will be a lunar eclipse on January 21, 2019.

(GW) Average global temperatures will continue to rise as a consequence of global warming.

(R) By next week, the milk in the refrigerator will be either gone, or spoiled.

Furthermore $(\mathrm{E}),(\mathrm{GW})$ and $(\mathrm{R})$ are not trivially true. Notice that the following future contingents are false.

$\left(\mathbf{E}^{-}\right)$There will be no lunar eclipse on January 21, 2019.

$\left(\mathbf{G W}^{-}\right)$Average global temperatures will begin to drop in 2019. 
$\left(\mathbf{R}^{-}\right)$By next week, the milk in the refrigerator will still be there, and will be fresh.

We think that denying (E), (GW), and (R) would be highly unpalatable. These claims are guaranteed, provided the world keeps evolving in accord with the current laws of nature. What is special about the current laws of nature-what makes them worth attending to-is that they will remain true. This is what enables them to support inductive inferences about the future. Traditional Humeans work hard to give metaphysically acceptable explanations for induction; denying induction altogether is a cost not worth paying.

An objector could counter that $(\mathrm{E}),(\mathrm{GW})$, and $(\mathrm{R})$ are not true, but that we are mistaking truth for some other status supported by induction, such as high probability. There are two possible versions of this objection; neither gets very far.

First, the objector might be claiming that while (E), (W), and (GR) are not true, they have high epistemic probability (or some other good epistemic status), so that we can justifiably be confident of them. But this version of the objection seems implausible. Typically, justified belief (or high credence) in a proposition is justified belief that the proposition is true. How can Growing-Block theorists justify placing high confidence in a proposition that, by their own lights, is not true? Why does such confidence merit the term belief, given that belief seems to aim at the truth of the content believed? Furthermore, what are we to make of the intuition that a prediction is vindicated when what is predicted comes about (i.e., when the prediction turns out true), and is not vindicated when what is predicted fails to come about (i.e., when the prediction turns out false)? On the first version of this objection, then, the connection between belief and truth becomes mysterious.

Second, the objector might be claiming that while (E) is not true, a closely related sentence is - a sentence that ascribes some metaphysical status to $E$.

$\left(\mathbf{E}^{*}\right)$ There is a high objective chance that there will be a lunar eclipse on January $21,2019$.

(Similarly for (GW) and (R).) Perhaps it makes sense to speak of a high objective chance for a proposition that lacks a truth value. Unlike belief, chance does not seem to aim at truth-it's not even clear that the objects of chances are propositions, rather than events. And perhaps knowledge of $\left(\mathrm{E}^{*}\right)$ is enough to guide the decisions of ordinary people and astronomers alike, regardless of (E)'s truth value. But even if all of this is granted, claiming that we know $\left(\mathrm{E}^{*}\right)$ is not enough solve 
the problem. We can still ask: what makes $\left(\mathrm{E}^{*}\right)$ true? $\left(\mathrm{E}^{*}\right)$ is about the future; it contains an embedded future tense operator. Furthermore, $\left(\mathrm{E}^{*}\right)$ is contingent: there could have been a low objective chance of a lunar eclipse on January 21, 2019. And ( $\left.E^{*}\right)$ 's truth needs an explanation, just as much as (E)'s truth would. So on the second version of this objection, there are still contingent truths about the future that need explanation. Premise 2, that there are non-trivial truths about the future, is true, then.

\subsection{The Briggs-Forbes Semantics for Future Truth}

We have argued that there are non-trivial truths about the future. But given that the future doesn't exist on the Growing-Block view, how are we to understand future truth? We will be thinking about it in terms of the view put forward by Briggs and Forbes [2012], since this is one of the few detailed accounts of future truth on the Growing-Block view.

Briggs and Forbes give a formal characterization of truths about the future using a collection of abstract ersatz times - maximal consistent sets of tensed propositions. Our world is made up of concrete times-collections of concrete things, such as shoes, ships, and sealing wax, which exist simultaneously with one another. Each concrete time is represented by an ersatz time. (On the other hand, not every ersatz time represents a concrete time; some correspond to ways concrete times might have been, but no concrete time actually is.) Sequences of ersatz times form timelines, which act as ersatz possible worlds, modelled on the worlds of Robert Merrihew Adams [1974]. The actual world is a collection of concrete times arranged in a temporal order, while ersatz timelines are collections of ersatz times arranged in temporal order.

Unlike the actual world, which grows as time passes, ersatz timelines are static and unchanging. As time passes, a series of different ersatz timelines come to represent, and then cease to completely represent, the same concrete world. According to Briggs and Forbes, one ersatz timeline is actualized-i.e., accurately represents all and only the things in the concrete actual world. Other ersatz timelines are feasible - they accurately represent the concrete actual world, and more - things and events that may come to exist in the future. Every feasible timeline overlaps the actualized timeline: the actualized timeline forms the initial segment of every feasible timeline. The feasible timelines are a subset of the possible timelinesthose compatible with constraints on how the future unfolds. This distinction between the feasible and the possible will be important later, in 6.3.2.

Each timeline, when taken together with all of its feasible timelines, generates 
a tree-like model structure composed of partially overlapping timelines. These timelines share initial segments with each other, but may diverge in later segments. The actualized timeline, together with all of its feasible timelines, can be represented in a treelike diagram.

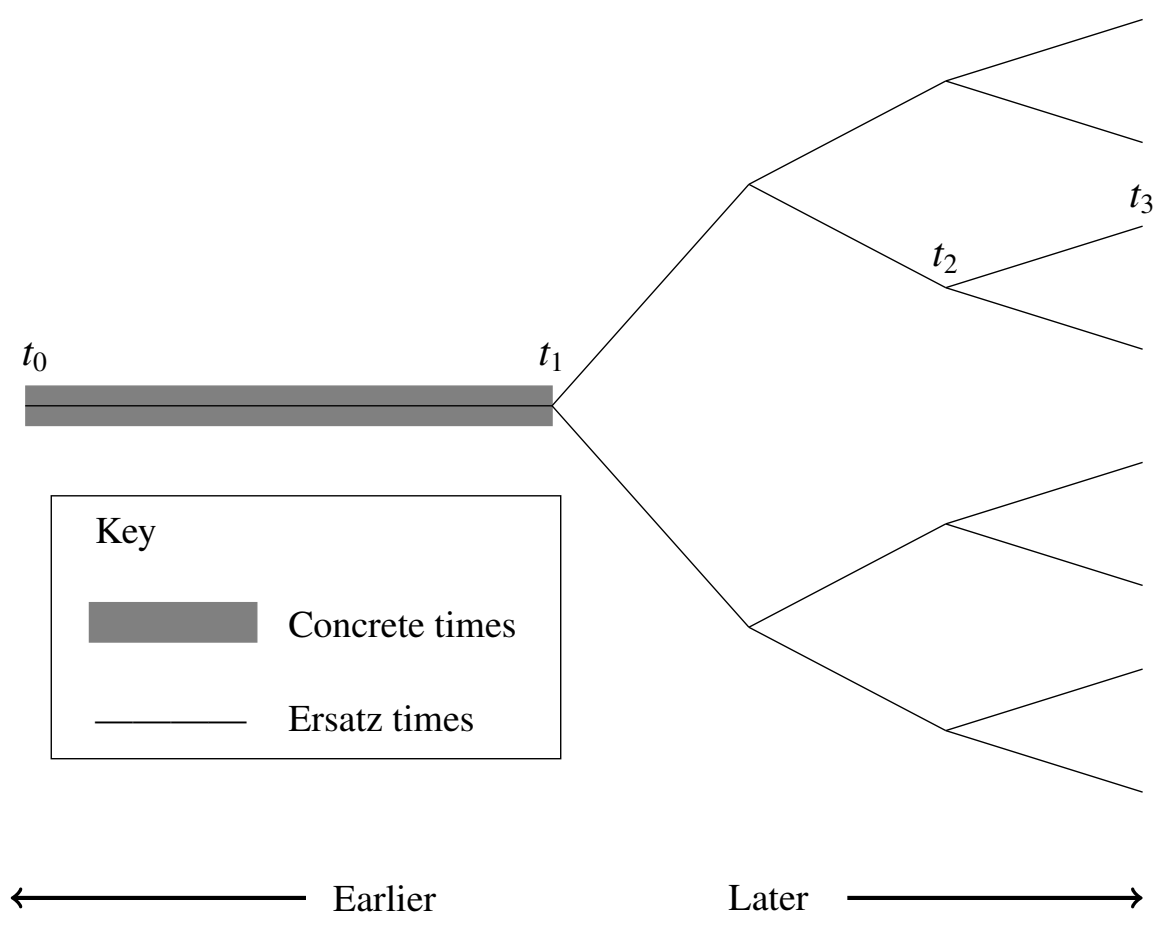

Timelines are truncated branches of the tree; they begin at the root, but need not extend all the way outward to a leaf. In the diagram, the actualized timeline runs from $t_{0}$ to $t_{1}$. One feasible timeline runs from $t_{0}$ to $t_{2}$ and stops; another runs from $t_{0}$ all the way to $t_{3}$.

This tree-like model structure allows Briggs and Forbes to model contingent future truths: they show how their theory can accommodate the supervaluational semantics of Stalnaker and Thomason [1970]. ${ }^{2}$ According to the supervaluational proposal, claims about the future, like $\mathrm{E}, \mathrm{GW}$, and $\mathrm{R}$ are true iff they are true on all feasible extensions of the actualised timeline, and false if true on no feasible timelines, and neither true nor false if true on some but not all feasible extensions

\footnotetext{
${ }^{2}$ Briggs and Forbes also consider two other semantic proposals, one three-valued and one intuitionist, which give slightly different treatments of logically complex sentences. The difference between these proposals is orthogonal to our main point, so we will set it aside.
} 
of the actualised timelines. In this section we have argued that there are at least some non-trivial claims that are true on all feasible extensions of the actualised timeline - that is, that any way the future will unfold will be one on which such a claim is true.

\section{The Need for Truthmakers}

So there are true, non-trivial propositions about the future. But does there need to be something in the world that makes these propositions true? Perhaps not. Some truths are commonly held to lack truthmakers; maybe truths about the future belong in their company. Proposed examples of truths without truthmakers include negative truths [Smith, 1999], such as

(U) There are no unicorns.

universal generalizations (which are equivalent to negative existentials), such as

(REM) Everybody hurts.

claims about incompatibility [Melia, 2005], such as

(I) Being red is incompatible with being blue.

and this self-referential sentence proposed by Milne [2013]

(M) M lacks a truthmaker.

In addition, while it is not true that

(N) There is nothing.

it is surely possible that $(\mathrm{N})$, and were $(\mathrm{N})$ true, then it would have no truthmaker [Lewis, 2001]. Alas, future contingents are not like sentences (U)-(N). Even if (U)-(N) are counterexamples to truthmaker maximalism, they are all compatible with the weaker thesis that

Truth Supervenes on Being If something is true then it would not be possible for it to be false unless either certain things were to exist which don't, or else certain things had not existed which do [Bigelow, 1988, 133]. 
Truths like (U) and (REM) could only be false if some new thing existed to falsify them; similarly for (N) at worlds where it is true. (I) and (M) are necessary, and so supervene on being trivially: since there can be no change in their truth values, a fortiori there can be no change in their truth values without a change in what exists.

But future contingents (at least, future contingents that are positive, particular, and non-paradoxical) have no such excuse. Consider

(S) There will be a sea battle tomorrow.

(S) is the sort of positive, particular, and non-paradoxical sentence that ought, if true, to have a truthmaker. After all, the sentence

$\left(\mathbf{S}^{*}\right)$ There was a sea battle yesterday.

has a truthmaker if it is true (namely, yesterday's sea battle). What asymmetry could there possibly be between $(\mathrm{S})$ and $\left(\mathrm{S}^{*}\right)$, such that $\left(\mathrm{S}^{*}\right)$ requires a truthmaker while $(\mathrm{S})$ does not?

The Growing-Block theorist might reply that while (S) does not have a truthmaker, it WILL have a truthmaker, and that is good enough. Instead of Bigelow's dictum, the Growing-Block theorist might argue, we can make due with a weaker principle that appeals to irreducibly tensed claims:

Truth Supervenes on Being and Future Being If something is true, then it would not be possible for it to be false unless either certain things which [don't exist and WILL not exist] were such that they [either exist or WILL exist], or else certain things which [exist or WILL exist] were such that they [do not exist and WILL not exist].

The Growing-Block theorist could then argue that, while truths about the future do not have truthmakers, they WILL have truthmakers. ${ }^{3}$

The objection works as a defensive move, but it's hardly more persuasive than a bare denial that future truths have truthmakers. (Remember, we are considering the Growing-Block view. Future being is not just being that is located in the

\footnotetext{
${ }^{3}$ This is Ulrich Meyer's view [Meyer, 2013, 55]. On one possible reading, this is also the view held by Tooley [1997], who claims that, "one can give an account of the idea of a whole, dynamic world only if one employs both the concept of being actual as of a time and the concept of the totality of existence-both temporal and non-temporal" [41]. Tooley also holds that truth simpliciter is bivalent $[153,311]$. Thus, truth simpliciter, for Tooley, would seem to supervene on being and future being.
} 
future, for the Growing-Block theorist holds that there is no being in the future.) It's logically possible that there be truths about the future without truthmakers; but such truths would cry out for explanation or grounding. Positing that such truths WILL have truthmakers doesn't help with the general project of explaining or grounding them; it leaves us with at least as many unexplained and ungrounded phenomena as we had before.

To see why there is a problem with grounding, consider Ted Sider's accusation that hypothetical properties (presumably including such temporal properties) are cheating:

What seems common to all cheats is that irreducibly hypothetical properties are postulated, whereas proper ontology should invoke only categorical, or occurrent, properties and relations. Categorical properties involve what objects are actually like, whereas hypothetical properties 'point beyond' their instances [Sider, 2001, 41].

Claims that some non-trivial proposition about the future is made true by something that WILL exist, but does not exist (in the least restricted sense of exist we can muster) must involve reality pointing beyond itself. The Humean cannot accept this, because their reasons for being suspicious of necessary connections between distinct existences are due to such necessary connections involving some local, particular matter of fact pointing beyond itself. The objection the Humean has to irreducible modality is at heart the same objection Sider has to hypothetical properties. So the Humean would be failing to follow the spirit of their own view if they accepted an appeal to what WILL exist but doesn't.

We conclude that some future contingents have truth values, and at least some of those with truth values have truthmakers, and so that premise 3 is true. That just leaves premise 4 to be defended: if some propositions about the future are made true by some thing (or things) not in the future, then there are irreducible necessary connections between distinct existents.

\section{Irreducible Necessary Connections}

Our argument for premise 4 depends crucially on the proposition

(NC) there are irreducible necessary connections between distinct existents.

We begin by explaining in more detail what we mean by (NC), laying out a sufficient condition for (NC) to obtain. We then use an example to argue that if some 
propositions about the future are made true by something (or things) not in the future, this sufficient condition is met, so that NC obtains. Furthermore, we argue that the posited necessary connections are irreducible. Thus, by conditional proof,

4. If some propositions about the future are made true by something (or things) not in the future, then there are necessary connections between distinct existents.

\subsection{What Are Necessary Connections Between Distinct Exis- tents?}

What does it mean to assert or deny (NC)? We break (NC) down into three parts ("distinct", "existents", and "necessary connections") to give a condition sufficient for it to obtain.

\subsubsection{Distinct}

Two individuals are distinct if they do not have any parts in common. But Humeanism should rule out not just irreducible necessary connections across pairs of distinct individuals (say, two billiard balls $a$ and $b$ ) but also irreducible necessary connections across non-overlapping collections of individuals (say, a collection of solid balls $A$ and a collection of striped balls $B$ ).

We can say that a collection of individuals $A$ is distinct from a collection of individuals $B$ whenever every individual in $A$ is distinct from every individual in $B$. If $A$ and $B$ are distinct collections of existents (in this sense of "distinct"), and there are necessary connections between the $A \mathrm{~s}$ and the $B \mathrm{~s}$, then there are necessary connections between distinct existents, even if no particular $a$ in $A$ bears a necessary connection to any particular $b$ in $B$.

One pair of distinct collections is the collection of events that occur wholly before a time $e$, on the one hand, and the collection of events that occur wholly after $e$, on the other. Since an arbitrarily chosen event that occurs wholly before $e$ has zero temporal overlap with an arbitrarily chosen event that occurs wholly after $e$, these two events must be distinct. Therefore, the collections must be distinct.

\subsubsection{Existents}

We take "existents" to be short for "possible existents". Humeanism aims to rule out not just cases in one actual existent necessitates another, but cases in which, 
for instance, an actual existent excludes some other possible existent (which, if it were to exist, would have no parts in common with the actual existent).

What is it for a collection of existents to be possible? According to a liberal view, a collection is possible just in case each element in the collection is possible on its own. According to a conservative view, a collection is possible just in case all the elements in the collection are compossible - that is, it is possible for them

to exist together. Adopting the conservative view yields a stronger reading of $4 \mathrm{c}$, and hence a stronger reading of 4 . We will therefore adopt the conservative view. (If the liberal view is true instead, then our argument will still succeed in establishing the weaker version of 4 .)

\subsubsection{Necessary Connections}

One commonly discussed type of necessary connection is necessitation: we will say that $A$ necessitates the $B$ just in case necessarily, if every $a$ in $A$ exists, then every $b$ in $B$ exists.

However, our example draws on a different type of necessary connection: exclusion. We will say that $A$ excludes $B$ just in case necessarily, if every $a$ in $A$ exists, then it is not the case that every $b$ in $B$ exists. Exclusion, like necessitation, is a modal link between possible existents that requires some sort of explanation.

\subsubsection{A Sufficient Condition}

Here is a sufficient condition for the truth of (NC):

There could have been a collection of individuals $A$, and there could have been a collection of individuals $B$, such that

i. each $a$ in $A$ is distinct from each $b$ in $B$, and

ii. $A$ excludes $B$, i.e., if every $a$ in $A$ exists, then it is not the case that every $b$ in $B$ exists.

\subsection{Our Example}

We have outlined a sufficient condition for the truth of (NC). We now give a representative example in which a proposition about the future is made true by something (or things) not in the future, and argue that in our example, this sufficient condition is met. Since our example does not rely on any specific feature of the 
proposition in question, we conclude that in general, if some proposition about the future is made true by something (or things) not in the future, then there are necessary connections between distinct existents.

Consider the following non-trivial proposition about the future

(E) There will be a lunar eclipse on January 21, 2019.

and suppose it is made true by past and present things. We will then show that on this assumption, there are necessary connections between distinct existents. Furthermore, there is nothing special about $(\mathrm{E})$, so our argument shows that, if there is any truth about the future made true by something (or things) not in the future, then there are necessary connections between distinct existents.

To lay out the argument, we will need to name a few things. Call the actual timeline @, and let $e$ be last time in @. Our timeline will grow into a longer timeline $T^{+}$that witnesses (E): $T^{+}$states that there is a lunar eclipse on January 21, 2019. However, since (E) is a non-trivial truth, its negation is perfectly possible. Consider a possible future in which there is no lunar eclipse on January 21, 2019, due to some lunar mishap. Call the timeline consisting of the actual present, followed by that possible future, $T^{-}$. We draw this situation in the figure below.
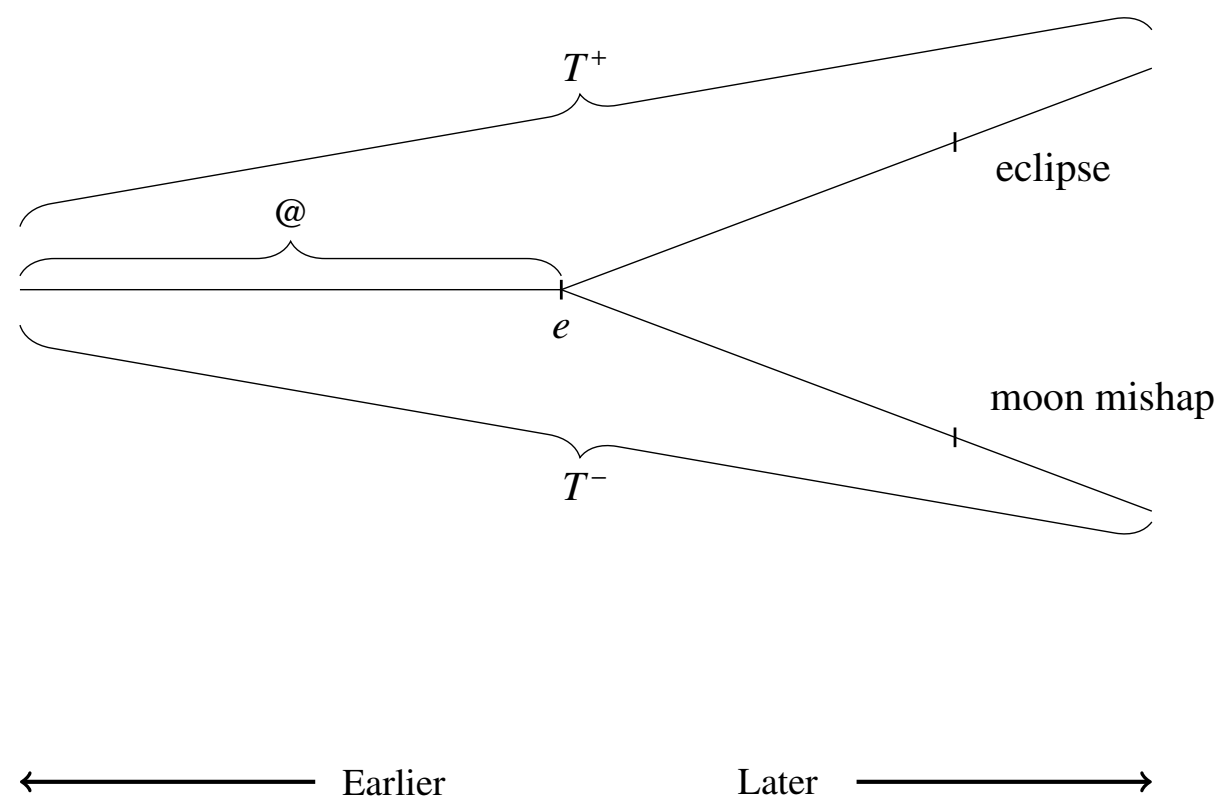

Later

We can then argue as follows. 
1. (E) is a true proposition about the future, made true by something (or things) not in the future (for conditional proof).

2. No possible timeline agrees with @ about what exists before $e$ and agrees with $T^{-}$about what exists after $e$ (from 13).

3. The sequence of events that occurs in @ is possible (since what is actual is possible).

4. The sequence of events in $T^{-}$that occurs after $e$ is possible (by stipulation).

5. There are necessary connections between distinct existents (from 14, 15, and 16).

6. If (E) is a true proposition about the future, made true by something (or things) not in the future, then there are necessary connections between distinct existents (from 13-17, discharging the assumption made for conditional proof).

The step from 13 to 14 is justified as follows. If a timeline agrees with @ about what exists before $e$, then the timeline agrees with @ about whether $(\mathrm{E})$ is true, because the whatever makes $(\mathrm{E})$ true is located before $e$. But a timeline at which (E) is true must contain a lunar eclipse on January 21, 2019; after all, (E) just says that there is a lunar eclipse on that date. But $T^{-}$contains the entirety of January 21,2019 , without a lunar eclipse, and so does every timeline that matches $T^{-}$after $e$. Therefore, no timeline agrees with @ before $e$ (so that it contains truthmakers for the claim that there is a lunar eclipse on January 21, 2019) and $T^{-}$afterward (so that there is in fact no lunar eclipse).

The inference from 17 is justified because the events of @ before $e$ and the events of $T^{-}$after $e$ are paradigm cases of distinct existents-especially by the Humean's lights. These events have no spatiotemporal overlap. And yet 14 states that there are necessary connections among them-connections that, by 15 and 16, cannot be factored into separate modal properties for the two events.

From 18, we still need a few more steps to get to premise 4. (E) was an arbitrary claim chosen for the sake of the example, and could be replaced with any other non-trivial truth about the future. Therefore, we are entitled to conclude

$4^{*}$ If some proposition about the future is made true by something (or things) not in the future, then there are necessary connections between distinct existents. 


\subsection{Irreducibility}

To get the rest of the the way from $4^{*}$ to premise 4 , we must think that these necessary connections between distinct existents are irreducible. In order to do so, we consider and reject two possible reductions along the lines the Humean might typically pursue. Since these reductions are the best candidates on the market, we should conclude that no reduction is likely to work.

\subsubsection{The Best-System Analysis}

For Humeans like Lewis [1986b], the laws are simply true generalizations of a special sort: they are theorems of the best system for summarizing truths about the world. Consider all the deductive systems with axioms formulated in a suitably natural language (i.e., one whose predicates pick out perfectly natural properties, and whose logical connectives are perfectly natural), all of whose theorems are true. Among such systems, the best is the one that most successfully balances the competing theoretical virtues of simplicity and strength. The later Lewis [1994] makes room for stochastic laws, which generate chances (in the form of statistical predictions), and which are judged by statistical fit (roughly, assigning a high probability to the actual world) as well as simplicity and strength. A proposition is nomologically necessary iff it is true at all possible worlds where the actual laws are true-no primitive modality required.

The most natural suggestion for a reduction of necessary connections between distinct existences, given that there are no future events to act as truthmakers, is that the truthmakers for propositions about the future are patterns in the dis-

tribution of local, perfectly natural properties in the past and present. For the Growing-Block theorist, perhaps what makes it the case that

(E) There will be a lunar eclipse on January 21, 2019.

is a combination of two factors:

FACTS about the current positions and masses of the moon, Earth, and sun, and

LAWS constraining the orbits of the moon and the earth about the sun, such as those in Brown's lunar theory [Brown, 1897].

For the Humean view we are considering, what gives the laws the status of laws is that they are theorems of the best system summarizing the past behaviour of the moon, the Earth and the sun-or perhaps the past behaviours of massive bodies 
more generally. So the past and present facts about the positions of objects in the universe make $(\mathrm{E})$ true.

Do the equations of Brown's lunar theory count as laws at @? We seem to have a dilemma. If Brown's equations do not count as laws at @, then it's hard to see how there could be enough laws to ground the truth of (E). Local particular matters of fact about the past entail nothing about the future. Perhaps there is something in the past - richer and stranger than local, particular matters of fact - that is capable of constraining the future. On the first horn of their dilemma, the Humean Growing-Block theorist needs to posit such things, but they, being richer and stranger than local particular matters of fact, are distinctly unhumean. Indeed, if they are to entail things about the future (but are not themselves future) they amount to necessary connections between distinct existences. The first horn of the dilemma, then, is that there are irreducible necessary connections between past and present things, and future things.

On the other horn, if Brown's equations do count at laws at @, then they are oddly toothless laws. Since $T^{-}$is a logical and metaphysical possibility, it is logically and metaphysically possible for @—laws and all-to develop into $T^{-}$. But the laws at @ forbid what happens at $T^{-}$. This toothlessness is not just strange; it undermines the ability of laws to do useful philosophical work. Laws are meant to predict propositions about the future, and they are meant to explain past and future regularities. Toothless laws-whether probabilistic or deterministic - can neither adequately predict nor adequately explain.

Consider first the role of laws as predictors of the future. A prediction about the future ought, at minimum, to be about the future, and not (only) about patterns in the past. But toothless laws do not seem to be about the future; they do not place any constraints on the way the future is. A prediction about the future should also somehow track the way the future is. But toothless laws track only facts about the past.

In addition to explaining the future, laws should explain past regularities. But toothless laws provide only toothless explanations. A good causal or nomological explanation of past regularities should be stable. Once a past course of events is fixed in history, a true explanation of it should stay true. If an event (say, a lunar eclipse) happened as a consequence of explanatory laws, then the explanation of the lunar eclipse should remain sound, even as new events accrue afterward. Consider the practical problems of having to carry out an inquiry where even the nomological explanations were unstable. One would have difficulty proceeding in the inquiry because the foundations would need constant revisiting.

But toothless laws are apt to undergo radical change, gaining and losing their 
lawlike character as new patterns emerge in the Growing-Block. The laws that were true yesterday may cease to be laws - and so cease to be explanatory - today. Some explanations are legitimately unstable; for example, an explanation of why we are not at Disneyland yet may appeal to facts whose truth value changes over time. But explanations of tenseless facts about the past should not be unstable. Toothless laws cannot offer adequate explanations, any more than they can offer adequate predictions.

The problem of toothless laws is closely related to Beebee [2000]'s observation that the Humean's conception of laws, on which they are simply useful true descriptions of particular matters of fact, is at odds with the intuition that laws govern, or ontologically ground, particular matters of fact. But the Humean Growing-Block theorist is in even worse circumstances than for Beebee's eternalist Humean. For the eternalist Humean, "the laws and current facts determine the future facts in a purely logical way: you can deduce future facts from current facts plus the laws. And this is just because laws are, in part, facts about the future." [Beebee, 2000, 578]. But for the Humean Growing-Block theorist, the laws are summaries of past and present regularities alone, so they do not even entail propositions about the future.

So, if the laws are merely best-system summaries of the past, then the Humean Growing-Block theorist is unable to make truths about the future true. If the laws are to entail truths about the future, they must be unhumean, since they involve necessary connections between distinct existences, or Humean laws fail to constrain future (and indeed past) explanations. Since we have argued in 5 that the Humean needs to make some non-trivial propositions about the future true, then the only way this can be done, without positing future things, is by having some necessary connections between the past and present things, and future things.

\subsubsection{Ersatz Times}

Perhaps we can instead reduce necessary connections to the ontology developed by Growing-Blockers Briggs and Forbes [2012]. One natural thought is that the constraints in how the future comes around (i.e. the difference between what is feasible and what is possible more broadly) can be analysed in non-modal terms, by appeal to feasible future timelines, and the way those feasible future timelines are. After all, our representative Growing-Blockers, Briggs and Forbes, hold that truths about the future covary with features of the feasible timelines, and these are just sequences of sets of propositions. Why not think that the necessary connections required to determine what is feasible can be analysed in terms of the 
feasible timelines?

Unfortunately, this view is unworkable; necessary connections cannot be analysed in terms of feasible timelines without an appeal to some other source of modality. The reason is the status of infeasible timelines. Our best modal and semantic theories commit us to infeasible timelines as much as feasible timelines. Philosophers model infeasible ways things could have been: for the physical, the metaphysical, the mathematical and logical readings of could. Some philosophers even wish to model ways things couldn't have been-the impossibilities. If feasible timelines correspond to ways things might feasibly have been, then by the same token, infeasible timelines should correspond to ways things could not feasibly have been. If feasible timelines contain no primitive modality-they are just one thing after another-then we could recombine those things in various ways to create alternative, infeasible timelines in which strange things happen, e.g. water flowing up hill. Without irreducible modality to pick out which are the feasible timelines and which are not, the Humean cannot tell the infeasible timelines from the feasible ones, in order for the necessary connections to be analysed in terms of the feasible timelines.

If feasible timelines were a different kind of thing from infeasible timelines, the Humean would have a way out of this problem. Growing-Block theorists are under heavy pressure to say that feasible and infeasible timelines are the same kind of thing, however. The Growing-Block theorist cannot claim that feasible timelines are concrete without giving up on one of the central tenets of her viewthe unreality of the future. Because infeasible timelines are generated by Humean recombination, they will be the same kind of thing as feasible timelines-nothing intrinsic to a timeline would make it infeasible rather than feasible.

But if there are infeasible timelines, and they are the same sorts of things as feasible timelines, then necessary connections cannot be reduced to feasible timelines alone. They must be grounded in the timelines together with whatever makes it the case that those timelines are the feasible ones. Otherwise, what could explain why a timeline containing an ersatz lunar eclipse is inevitable, while its sister timeline containing an ersatz future in which there is not such an eclipse is infeasible? Feasible timelines by themselves are not up to the job. Perhaps we could have some method that picks out some of the timelines as the feasible ones. In his ersatzer Presentist account, Bourne [2006] proposes an extra ingredient to sort the feasible from the infeasible timelines. This ingredient is a primitive 'E-relation' that relates ersatz times together to create ersatz timelines. Ersatz timelines, according to Bourne, are just those related to each other and to the concretely instantiated time by the E-relation. Some perfectly possible ersatz times 
are not E-related to the actual present-so these ersatz times do not accurately represent the past.

While this view may seem to give us the means to sort the feasible from the infeasible, the E-relation is incompatible with Humean supervenience. The Erelation is a primitive relation that does not supervene on any local and particular matters of fact and/or the perfectly natural spatio-temporal relations between them. There are many ways ersatz times could be ordered, but nothing intrinsic to the ersatz-times picks out which ones are E-related, and being ersatz, ersatz times are not related by perfectly natural spatio-temporal relations. The E-relation is an appeal to irreducible modality, and as such it does not allow a way to analyze necessary connections in non-modal terms - the modality gets brought back in by the E-relation. Using feasible timelines to avoid irreducible necessary connections, then, relies on some method of setting the feasible timelines apart from the infeasible ones, but that separating itself depends on the necessary connections we were trying to analyze away. We don't see another alternative reduction of the necessary connection between distinct existences for the Humean. We have argued in this section that the most plausible reduction of such a necessary connection won't work, so we have argued for premise 4.

\section{Conclusion}

We aimed to show that defenders of Humean Supervenience and defenders of the Growing-Block view should not be happy bedfellows. We think we have done so. As premise 1, for reductio we assumed the conjunction of Humean Supervenience and the Growing-Block view-the Humean Growing-Block view. We have argued that any sensible view should think there are non-trivial truths about contingent future events (premise 2) and that these truths must be made true (premise 3). The Humean Growing-Block view either fails to accept there are such truths or gives an inadequate account of what makes them true. This is because irreducible necessary connections between distinct existences are needed to make non-trivial truths true without appeal to future things (premise 4). On the basis of our master argument, given the truth of premises 2-4, we must reject the Humean GrowingBlock view. While we've briefly motivated the Growing-Block view and Humean Supervenience, and we think that both are independently attractive views, nothing we've said here constitutes a full defence of either. Our aim has simply been to show that if you find yourself committed to one of these views, you should not hold the other. 


\section{References}

Robert Merrihew Adams. Theories of actuality. Noûs, 8(3):211-231, 1974.

Aristotle. Nicomachean Ethics. Oxford University Press, 2002.

Helen Beebee. The non-governing conception of laws of nature. Philosophy and Phenomenological Research, 61(3):571-594, 2000.

John Bigelow. The Reality of Numbers: A Physicalist's Philosophy of Mathematics, volume 40. Oxford University Press, 1988.

Craig Bourne. A Future for Presentism. Oxford University Press, 2006.

Rachael Briggs and Graeme Forbes. The real truth about the unreal future. Oxford Studies in Metaphysics, 7, 2012.

Ernest Brown. Theory of the motion of the moon. Memoirs of the Royal Astronomical Society, 53:39-116, 1897. URL https://archive.org/details/Theory0fTheMotion0fTheMoon.

David Lewis. On the Plurality of Worlds. Oxford University Press, 1986a.

David Lewis. Philosophical Papers, volume II. Oxford University Press, 1986b.

David Lewis. Humean supervenience debugged. Mind, 103(412):473-490, 1994.

David Lewis. Truthmaking and difference-making. Noûs, 35(4):602-615, 2001.

Joseph Melia. Truthmaking without truthmakers. In Helen Beebee and Julian Dodd, editors, Truthmakers: The Contemporary Debate, page 67. Clarendon, 2005.

Ulrich Meyer. The Nature of Time. Clarendon Press, 2013.

Kristie Miller. Backwards causation, time, and the open future. Metaphysica, 9 (2):173-191, 2008.

Peter Milne. Not every truth has a truthmaker ii. Analysis, 73(3):473-481, 2013.

Eric Olson. The passage of time. In Robin Le Poidevin, editor, The Routledge Companion to Metaphysics. Routledge, 2009. 
Theodore Sider. Four Dimensionalism: An Ontology of Persistence and Time. Oxford University Press, 2001.

Barry Smith. Truthmaker realism. Australasian Journal of Philosophy, 77(3): 274-291, 1999.

Robert C. Stalnaker and Richmond H. Thomason. A semantic analysis of conditional logic. Theoria, 36(1):23-42, 1970.

Michael Tooley. Time, Tense, and Causation. Clarendon Press, Oxford, 1997. 